\title{
Efficiency of Animal (Cow, Donkey, Chicken and Horse) Bones, in Removal of Hexavalent Chromium from Aqueous Solution as a Low Cost Adsorbent
}

\author{
Nworu Jerome Sunday ${ }^{1, ~ *}$, Enemose Edith Ajirioghene ${ }^{1}$, Osideru Oluwatobi Omotayo ${ }^{2}$, \\ Emmanuel Okon Asukwo \\ ${ }^{1}$ Department of Chemistry, Nigeria Maritime University, Delta, Nigeria \\ ${ }^{2}$ Department of Chemistry, University of Ibadan, Uyo, Nigeria \\ ${ }^{3}$ Department of Mechanical Engineering, Nigeria Maritime University, Delta, Nigeria
}

Email address:

Jeromenworu102@gmail.com (N. J. Sunday)

${ }^{*}$ Corresponding author

\section{To cite this article:}

Nworu Jerome Sunday, Enemose Edith Ajirioghene, Osideru Oluwatobi Omotayo, Emmanuel Okon Asukwo. Efficiency of Animal (Cow, Donkey, Chicken and Horse) Bones, in Removal of Hexavalent Chromium from Aqueous Solution as a Low Cost Adsorbent. American Journal of Applied Chemistry. Vol. 7, No. 1, 2019, pp. 1-9. doi: 10.11648/j.ajac.20190701.11

Received: January 23, 2019; Accepted: February 25, 2019; Published: March 18, 2019

\begin{abstract}
As a low cost adsorbent source, a mixture of activated animal bones has been investigated on their efficiency in chromium ion removal from aqueous solution. Adsorption parameters such as contact time, biosorbent size, $\mathrm{pH}$, biosorbent dosage, temperature and concentrations were investigated. Maximum adsorption of hexavalent chromium occurred at 35 minutes, $53 \mu \mathrm{m}$ size of adsorbent, $\mathrm{pH}=6,70 \mathrm{mg} / \mathrm{L}$ of chromium ion, $3 \mathrm{~g}$ of adsorbent dosage and $303 \mathrm{~K}$. The experimental data from the adsorption processes were all tested with Langmuir and Freundlich isotherms. Both isotherms showed good correlations. The higher value of $\mathrm{R}^{2}=0.9938$ from Freundlich isotherm over the $\mathrm{R}^{2}=0.99$ value of Langmuir isotherm showed a better fitness of the adsorption process to Freundlich isotherm over Langmuir model. It can be concluded that any activated carbon from the bones of Cow, Donkey, Chicken and Horse are effective and can be used in industries for removal of hexavalent chromium.
\end{abstract}

Keywords: Biosorption, Activated Carbon, Adsorption, Chromium, Animal Bones

\section{Introduction}

Heavy metals such as chromium are present in water effluents from several chemical industries. These metals are environmentally hazardous and will accumulate in the food chain and could cause much side effects. The environmental regulations and monitoring which are related to the discharge of these heavy metals makes it possible to establish processes for enhance removal from waste water. Activated carbons because of their high surface area to volume ratio, chemical nature of their surface and microporous character have been explored for this purpose [9, 10]. The applications of activated carbons are vast, which led to the current research on the usefulness of animal bones as an efficient adsorbent for heavy metal removal from liquid industrial wastes.
Several production industries such as mining, petroleum refining, electroplating, metal processing, tanneries, textiles, pesticides, paint manufacturing, photographic printing and industries and battery manufacturing releases plenty of heavy metals and are normally found in industrial waste-waters $[1$, $2,7,12,21]$. Heavy metals at high concentrations from industries can easily pollute a given environment, affecting the entire ecosystem since soil and water serves as a reservoir for heavy metals $[6,21]$. These heavy metals are environmental pollutants which have high negative impacts and have the ability to modify the chemical and physical properties of water and soils $[8,9,12,17,21]$. Also, high concentration of heavy metal in drinking water, irrigation water, industrial waste-water has direct negative effects on human health. Heavy metals on soils are easily absorbed through the roots of plants and are highly chronic to the 
health of the consumers $[4,21]$. Purification of waste-water contaminated by heavy metals are carried out by several processes such as ion exchange membranes [9, 10], flocculation by coagulation $[14,16,20]$, electrochemical processes $[9,11]$, chemical precipitation $[4,18]$ and through adsorption processes [3, 5, 13, 18, 19]. However, among these methods, adsorption process is a very cost free technique making use of environmental wastes as an adsorbent, thereby keeping the environment clean from these wastes. There are many known substances that has the ability of adsorbing ions when exposed on their surfaces such as silica gel, alumina, activated charcoal, earth fullers, clays etc $[29,32]$.

\subsection{Adsorption Processes}

When a solid surface is brought in contact with a liquid or gas molecules from the gas or liquid tends to collect at the surface of the solid. This process of a collection of gas or liquid molecules on the surface of the solid is known as adsorption. Adsorption is a surface phenomenon which involves the aggregation of molecular species onto an interface or a surface. The aggregated molecular species that gets adsorbed on the interface are termed the adsorbate and the interface on which the adsorption takes place is called the adsorbent [25, 28, 30-32].

Adsorption is an exothermic process and the enthalpy change is always negative. Forces of attraction always exist between the adsorbent and the adsorbate and due to these forces of attraction, heat energy is released to the surrounding. So adsorption is an exothermic process. When the adsorbate molecules are adsorbed on the interface, there will be a restriction to the movement of the adsorbate and this leads to decrease in the entropy of adsorption [4, 12, 15].

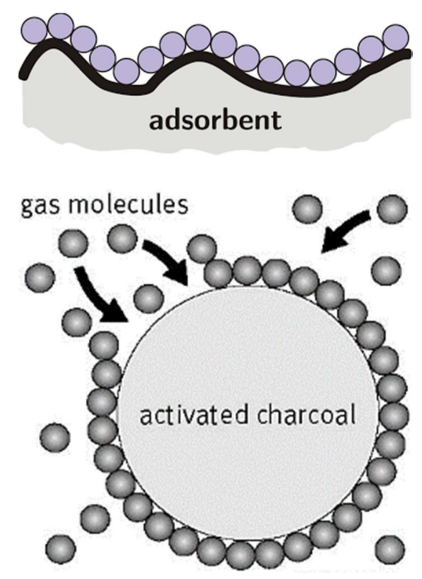

Figure 1. Adsorption processess.

Adsorption is a spontaneous process occurring at nonuniform rate and the rate always increase at the initial stage and gradually decreases as time of adsorption increases. During adsorption, the concentration at the interface of the adsorbent is different from that in the bulk solution. For reaction or process to be spontaneous, there must be decreases in free energy of the system i.e. $\Delta G$ of the system must have negative value $[10,15,17]$.

$$
\Delta \mathrm{G}=\Delta \mathrm{H}-\mathrm{T} \Delta \mathrm{S}
$$

Positive result of this research work could suggest the huge economic benefits of these animal bones which could be beneficial to the developing countries where these animals are largely reared and could be easily incorporated in the development of appropriate processes and technologies.

\subsection{A Review on Hexavalent Chromium Adsorption}

In waste water treatment, chromium is one of the major heavy metals in consideration. The environmental toxicity level of chromium is high, which accounts for the priority given to it for environmental regulation. The removal of these hexavalent chromium has best been achieved by adsorption processes. So many adsorbents have been used for this purpose, such as fly ash, polymer, carbon nanotubes, clays, silica gel, zeolites, peat moss, chitosan, biosorbent, food waste, etc. At the recent time, many adsorbents have been developed by researchers, which can be impregnated or modified for improved capacity of their adsorption. The river sand has been used for adsorption of hexavalent chromium which recorded $0.15 \mathrm{mg} / \mathrm{g}$ adsorption capacity with $74.30 \%$ removal capacity [40]. Lee et al. (2010) have also prepared Manganese-coated sand by wet coating method and reported improvement in adsorption capacity up to $6.27 \mathrm{mg} / \mathrm{g}$ [41]. Silica gel, alumina, and magnetite were explored as adsorbents for adsorption of hexavalent chromium. The removal capacity for hexavalent chromium was observed to be more than $80 \%$ [42]. A cross-linked graft copolymer of [2-(metha-cryloyloxy)ethyl] trimethylammonium chloride on poly(vinyl alcohol) has been reported and it is cross-linked by glutaraldehyde for the adsorption of hexavalent chromium, which shows adsorption efficiency of $6.69 \mathrm{mg} / \mathrm{g}$ from aqueous solution at $300 \mathrm{~K}$ [43]. The literature survey shows several polymers with their good adsorption capacity such as, polyaniline/poly ethylene glycol with 109.9 and $68.97 \mathrm{mg} / \mathrm{g}$ respectively [44]. The Chromium (VI) percentage removal capacity was reported for quaternized cross-linked poly (4-vinylpyridines) [45] and aminated polyacrylonitrile fibers [46] as $97.4 \%$ and $96 \%$ respectively. The adsorbents reported with their adsorption capacity such as, condensed-tannin gels derived from a natural polymer with polyhydroxyphenyl group $(287 \mathrm{mg} / \mathrm{g})$ [47], short chain polyaniline (PANI), a polymer was synthesized on the surface of jute fiber $(62.9 \mathrm{mg} / \mathrm{g})$ [48], ethylene diaminemodified cross-linked magnetic chitosan resin $(51.813 \mathrm{mg} / \mathrm{g}$ at $293 \mathrm{~K}$ ) [49]. Adsorption using activated carbon is an attractive choice for chromium removal for efficiency removal and pollutant alteration. This has triggered the interest of researchers to source for any possible means for treatment of waste water which contains chromium through adsorption processes. This work is aimed at determination of the adsorption capacity of animal bone mixtures in chromium metal removal. 


\section{Materials and Methods}

\subsection{Sample Collection and Charcoal Preparation}

The bone samples of cow, donkey, chicken and horse were collected from a local slaughter house in Ezzangbo, Abakaliki, Nigeria. Samples were washed and oven dried at $105^{\circ} \mathrm{C}$. Accurately weighed and dried bone samples of cow, donkey, chicken and horse were carbonized in a closed crucible at $400^{\circ} \mathrm{C}$, using Fisher Scientific Isotemp Muffle Furnace, for 1 hour.

\subsection{Preparation of Activated Carbon}

The carbonized bone was then activated by measuring $200 \mathrm{~g}$ of each of the crushed samples into a beaker which was then made into sludge with $250 \mathrm{ml}$ of $2 \mathrm{M}$ hydrochloric acid. The resulting mixture was heated for one hour at $80^{\circ} \mathrm{C}$, filtered off and washed with distilled water to remove the acid on the surface of the carbons and then dried in an oven at $105^{\circ} \mathrm{C}$ for 24 hours. The dried sample was sieved to $2 \mathrm{~mm}$ size and kept in a small tray. This procedure was done for all carbonized bone sample.

\subsection{Adsorbate Preparation}

Chemicals reagents used were of analytical reagent grade. A stock of chromium solution was prepared by dissolving $2.83 \mathrm{~g}$ of potassium dichromate $\left(\mathrm{K}_{2} \mathrm{Cr}_{2} \mathrm{O}_{7}\right)$ in a one litre flask, with a distilled water and further diluted to desired concentrations containing 20,50,70,80,100, 150, and 200 $\mathrm{mg} / \mathrm{L}$ of chromium in aqueous phase standard solutions. The $\mathrm{pH}$ of the solutions was maintained using $0.5 \mathrm{M} \mathrm{HCl}$ and $0.5 \mathrm{M} \mathrm{NaOH}$ solutions.

\subsubsection{Effect of Contact Time on \% Biosorption of Chromium Biosorbent - A Mixture of Animal Bones}

In a prepared standard solution of a Chromium metal (Co $=20 \mathrm{mg} / \mathrm{L}), 0.5 \mathrm{~g}(10 \mathrm{~g} / \mathrm{L})$ by weight of the adsorbent with a pore size of $53 \mu \mathrm{m}$ was agitated in a mechanical shaker (250rpm) for 1, 3, 5, 10, 15, 20, 25, 30, 35, 40, 45, 50, 55, 60 minutes at Temperature, $\mathrm{T}=303 \mathrm{~K}$. The volume of the Chromium aqueous solution is $50 \mathrm{~mL}(\mathrm{pH}=6)$. Sample was then filtered with a Whatman filter paper, stored a white bottle and subjected to Atomic Absorption Spectrophotometer (Buck Scientific 210 VGP model).

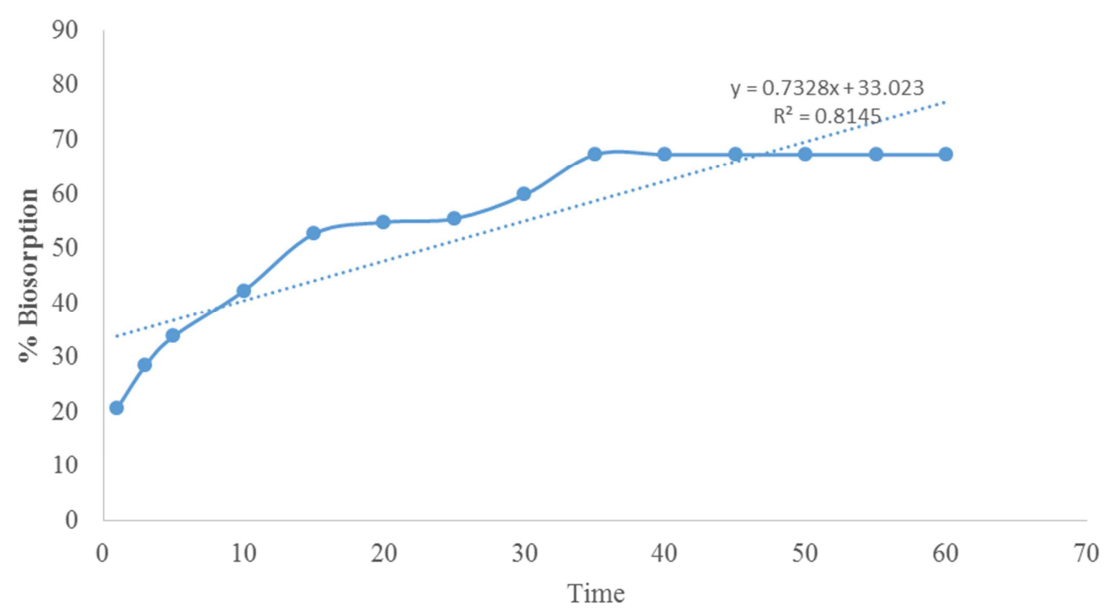

Figure 2. Effect of contact time on \% biosorption of Chromium Biosorbent-A mixture of animal bones. Agitation speed $=250$ rpm, Chromium concentration $=$ $20 \mathrm{mg} / \mathrm{L}, \mathrm{pH}=6$, Temperature $=303 \mathrm{~K}$, Adsorbent dosage $=10 \mathrm{~g} / \mathrm{L}$.

Contact time plays a very significant role during Chromium adsorption. The contact time for the adsorption of chromium metal by the adsorbate (animal bone mixture) was studied at different time intervals. Figure 2 showed the effects of contact time on Biosorption of chromium metal. From figure 2, there is a progressive increase in the percentage of chromium metal Biosorption from 1-30 minutes. Figure 2 also showed that there is an equilibrium Biosorption of chromium metal at the surface of the adsorbent from 35-60 minutes, with chromium concentration of $20 \mathrm{mg} / \mathrm{L}$ at $\mathrm{pH}=6$. At lower time of contacts between the adsorbate and the adsorbent (1-30 minutes), Biosorption was lower because of decreased time of collision. Also, increased collision time enhances chemical reaction [28, 33, 38].

\subsubsection{Effect of Biosorbent Size on \% Biosorption of Chromium Biosorbent - A Mixture of Animal Bones}

A $0.5 \mathrm{~g}(10 \mathrm{~g} / \mathrm{L})$ of the adsorbent with different sizes (53, $75,105,125,152(\mu \mathrm{m}))$ was agitated for 35 minutes (Optimum contact time) in a $50 \mathrm{~mL}$ of Chromium salt solution whose initial concentration was $\mathrm{Co}=20 \mathrm{mg} / \mathrm{L}$ at Temperature, $\mathrm{T}=303 \mathrm{~K}$. The $\mathrm{pH}$ of the aqueous solution $=6$. Samples were filtered with a whatman filter paper and filtrate was analyzed using Atomic Absorption Spectrophotometer (Buck Scientific 210 VGP model). 


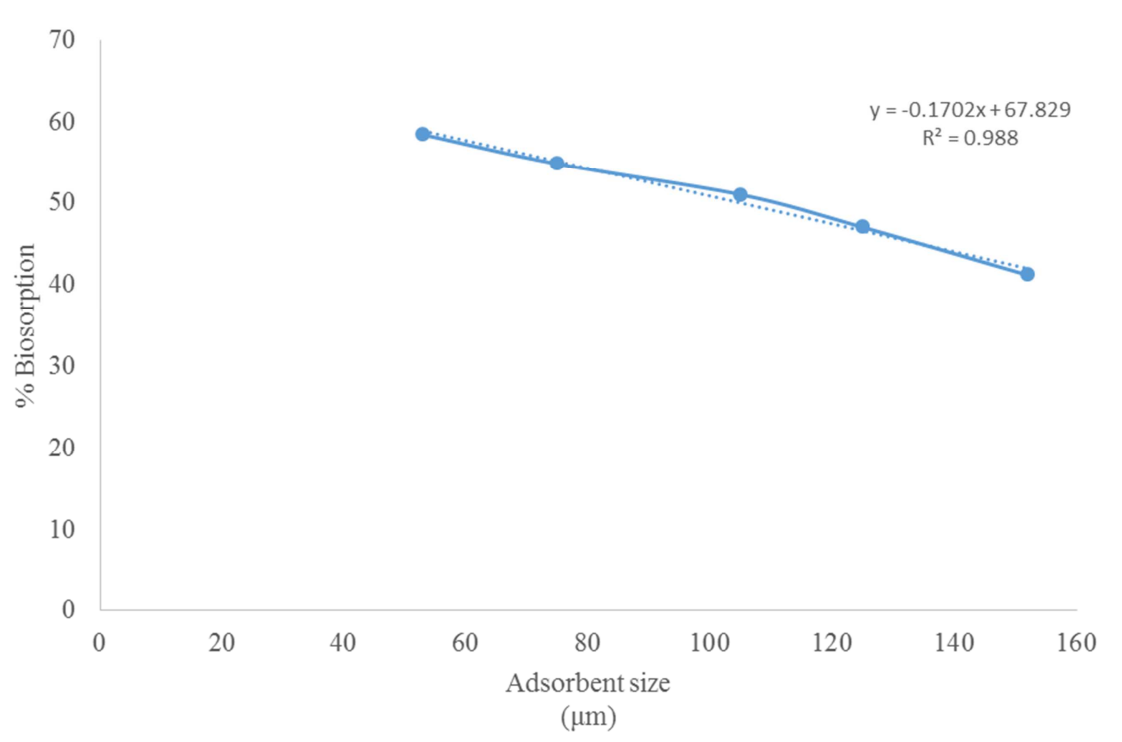

Figure 3. Effect of biosorbent size on \% biosorption of Chromium Biosorbent- A mixture of animal bones. Agitation speed $=250$ rpm, Chromium concentration $=20 \mathrm{mg} / \mathrm{L}, \mathrm{pH}=6$, Temperature $=303 \mathrm{~K}$, Adsorbent dosage $=10 \mathrm{~g} / \mathrm{L}$.

The effect of biosorbent size on percentage sorption of chromium metal is represented figure 3. From the graph, higher adsorbent sizes showed lower adsorption of chromium metal. Higher percentage removal and chromium metal uptake was noticed when adsorbent size of $53 \mu \mathrm{m}$ was used for chromium metal adsorption.

\subsubsection{Effect of pH on \% Biosorption of Chromium Biosorbent - A Mixture of Animal Bones}

A $0.5 \mathrm{~g}(10 \mathrm{~g} / \mathrm{L})$ of the adsorbent with $\mathrm{pH}(2,3,4,5,6,7$, 8) was agitated for 35 minutes in a $50 \mathrm{~mL}$ of Chromium salt solution whose initial concentration was $\mathrm{Co}=20 \mathrm{mg} / \mathrm{L}$ at Temperature, $\mathrm{T}=303 \mathrm{~K}$. Acids and bases were used in the $\mathrm{pH}$ regulation. Samples were filtered with a whatman filter paper and filtrate was analyzed using Atomic Absorption Spectrophotometer (Buck Scientific 210 VGP model).

$\mathrm{pH}$ is one of the factors that influences adsorption processes. Figure 4 represents the effects of $\mathrm{pH}$ on percentage Biosorption of chromium metal on the adsorbent. From the graph, there is a linearity and progressive increase in the percentage of Biosorption of chromium metal from $\mathrm{pH}$ 2-6. From $\mathrm{pH}$ 7-8, showed a decrease in the percentage of adsorbate removal. Highest and lowest percentage of Biosorption was seen at $\mathrm{pH} 6$ [69.15\%] and $\mathrm{pH} 2$ [47.80\%] respectively. All other experiments were done at this optimum $\mathrm{pH}$. The result, showed that biosorption of chromium metal with mixture of animal bones (adsorbent) is more efficient at fairly acidic $\mathrm{pH}$ region of 6. From the research work [38]; acid condition at $\mathrm{pH} 1$ until 5, volcanic ash could remove methylene blue $76.59 \%$ till $100 \%$. After $\mathrm{pH} 5$ till $\mathrm{pH} 9$, capability of volcanic ash to adsorb methylene blue stayed on better in $100 \%$. It was mean that more alkaline condition of solution, methylene blue removed was many. Volcanic ash needed base surface condition to adsorb methylene blue compound. It indicated that base condition could take place hydroxide ion $(-\mathrm{OH})$ of siloxane and silanol on adsorbent surface. This condition made its interaction up and could adsorb methylene blue.

\section{Chart Title}

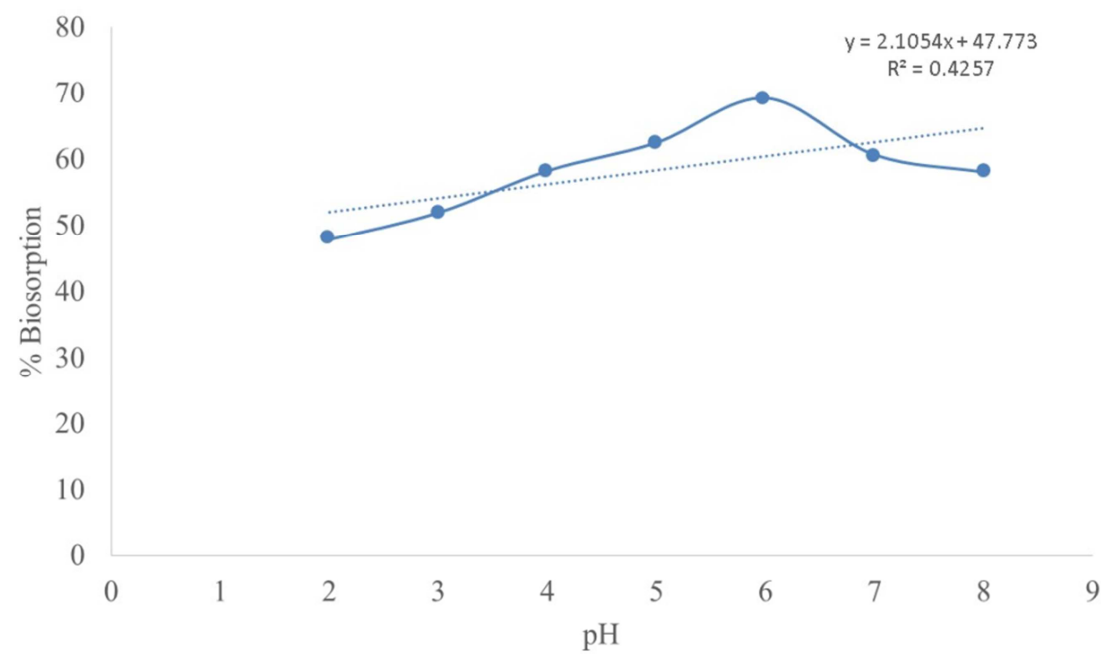

Figure 4. Effect of pH on \% biosorption of Chromium Biosorbent-A mixture of animal bones. 


\subsubsection{Effect of Biosorbent Dosage on \% Biosorption of Chromium Biosorbent - A Mixture of Animal Bones}

The adsorbent dosage was varied $(0.25,0.50,0.75,1.00$, $1.25,1.50,1.75,2.00,2.50,3.00)$. each dosage was agitated for 35 minutes in a $50 \mathrm{~mL}$ of Chromium salt solution whose initial concentration was $\mathrm{Co}=20 \mathrm{mg} / \mathrm{L}$ at Temperature, $\mathrm{T}=$ $303 \mathrm{~K}$. Samples were filtered with a whatman filter paper and filtrate was analyzed using Atomic Absorption Spectrophotometer (Buck Scientific 210 VGP model).

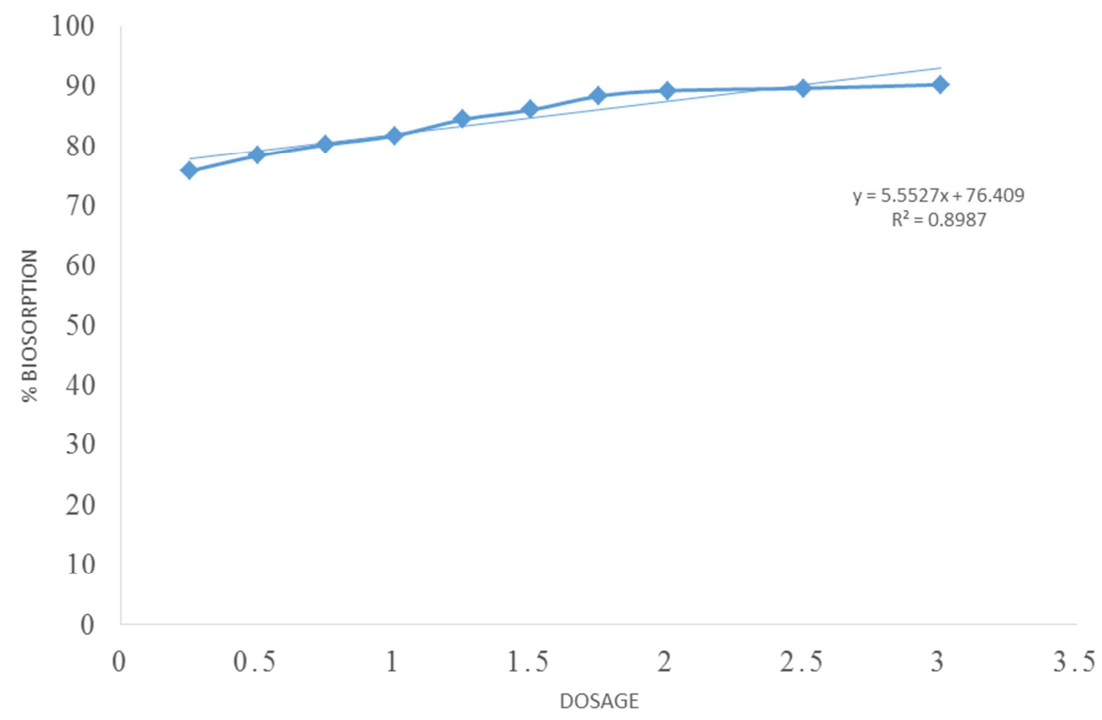

Figure 5. Effect of biosorbent dosage on \% biosorption of Chromium Biosorbent- A mixture of animal bones.

The variation of the dosage of the adsorbent mixture as represented in figure 5, showed that, mass increase of the adsorbent dosage causes linear increase of the percentage Biosorption. High mass of the adsorbents would adsorbent higher adsorbate on to their active pore surfaces because of their increased surface area [39]. Maximum adsorption was observed to be $90.30 \%$ at $3.00 \mathrm{~g}$ mass of the adsorbent. This indicates that, there will be an increase in adsorption of chromium with increased mass/dosage of the adsorbent. Adsorbent removal efficiency increases with increased in adsorbent dosage. This is as a result of increased availability of exchangeable sites for the adsorbate [39].

\subsubsection{Effect of Biosorbent Temperature on \% Biosorption of Chromium Biosorbent - A Mixture of Animal Bones}

A $0.5 \mathrm{~g}(10 \mathrm{~g} / \mathrm{L})$ of the adsorbent with $\mathrm{pH}(2,3,4,5,6,7$, 8) was agitated for 35 minutes in a $50 \mathrm{~mL}$ of Chromium salt solution whose initial concentration was $\mathrm{Co}=20 \mathrm{mg} / \mathrm{L}$ at Temperature, $\mathrm{T}=303 \mathrm{~K}$. Samples were filtered with a whatman filter paper and filtrate was analyzed using Atomic Absorption Spectrophotometer (Buck Scientific 210 VGP model).

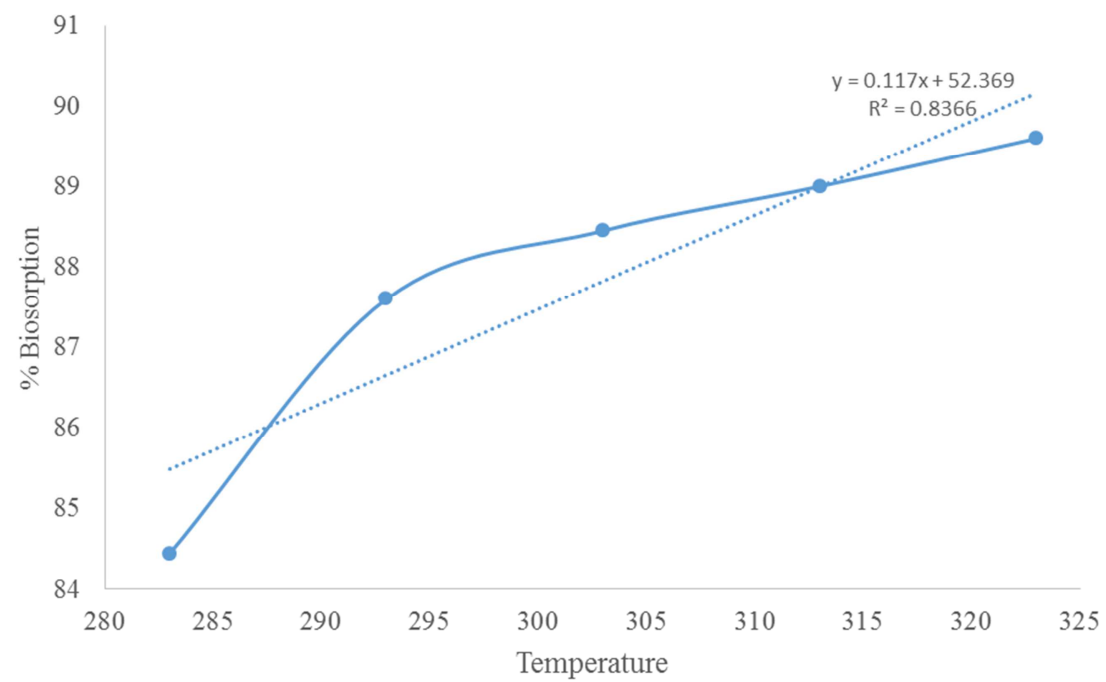

(K)

Figure 6. Effect of biosorbent temperature on \% biosorption of Chromium Biosorbent- A mixture of animal bones.

Figure 6 showed the temperature effect on percentage adsorption of chromium by the adsorbent. Maximum 
percentage adsorption occurred linearly with increasing temperature. At room temperature of $293 \mathrm{~K}$, chromium adsorption was very appreciable up to $87.60 \%$. Generally, it was observed that increase in temperature favours chromium adsorption with a mixture of these adsorbents.

\subsubsection{Effect of Initial Concentration of Aqueous Solution on \% Biosorption of Chromium Biosorbent-A Mixture of Animal Bones}

A $0.5 \mathrm{~g}(10 \mathrm{~g} / \mathrm{L})$ of the adsorbent was agitated with Chromium salt solution at varying initial concentrations (20, $50,70,80,100,150,200)$ at Temperature, $\mathrm{T}=303 \mathrm{~K}$ for 35 minutes (Optimum contact time). The volume of the Chromium aqueous solution is $50 \mathrm{~mL}$. Samples were filtered with a whatman filter paper and filtrate was analyzed using
Atomic Absorption Spectrophotometer (Buck Scientific 210 VGP model).

\subsubsection{Adsorption Isotherms}

The adsorption isotherm, which showed the amount of solute particle adsorbed per unit adsorbent was studied as a function of constant temperature and equilibrium concentration of the bulk solution (Figure 7). As stated in figure 7 for the adsorption isotherm for chromium adsorption. The isotherm has higher slope at low $\mathrm{Ce}$ and $\mathrm{qt}$ points because of the linear rise in the initial stage. This suggests that, at the initial stage of adsorption, accessible sites are numerous which defines the fitness of the isotherm to a monolayer coverage of chromium [50].

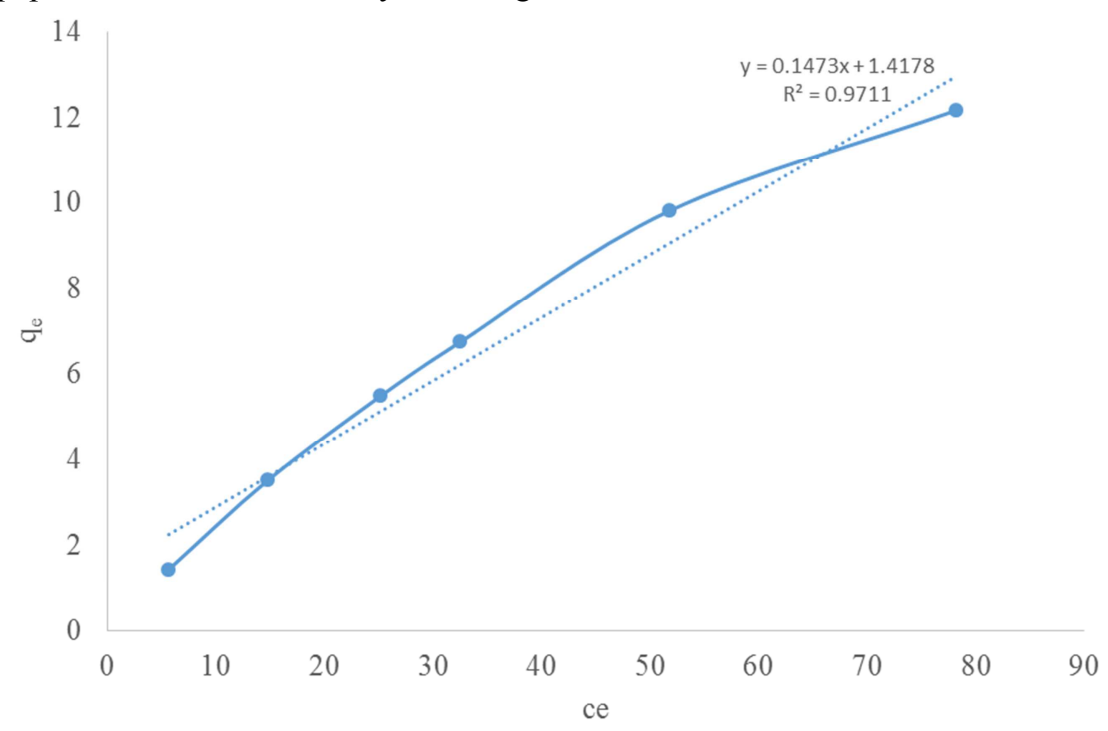

Figure 7. Adsorption isotherm for $\mathrm{Cr}$ adsorption. $T=303 \mathrm{~K}$, Time $=35$ minutes, $\mathrm{pH}=6$, Adsorbent dosage $=0.5 \mathrm{~g}$.

Results from the analysis were tested with both Langmuir and Freundlich isotherms. The isotherms are represented in figure 6 and 7 respectively. The Langmuir and Freundlich isotherms showed good R-squared values of 0.99 and 0.9938 respectively, which are almost a unity value, indicating a good fitness of the adsorbent on chromium adsorption.

\section{Langmuir Isotherm}

According to Langmuir isotherm model, adsorption only occur at the active sites of the adsorbent surfaces and upon completely filling the active pore sites by the adsorbate, further adsorption quenches. In Langmuir model of isotherm, the surface of the adsorbent is uniform, that is, all the adsorption pore sites are equal, no interaction of the adsorbed molecules, adsorption occurs through the same process and at the point of maximum adsorption, only a monolayer is formed: molecules of adsorbate do not deposit on other already adsorbed molecules of adsorbate, only on the free surface of the adsorbent. As shown in the Langmuir isotherm curve (Figure 8), the model showed a good fitness for the adsorption of chromium metal ion from aqueous solution with a good correlation coefficient $\mathrm{R}^{2}$ value of 0.99 .
The Langmuir isotherm model can be illustrated in the following Equation (1),

$$
\mathrm{C}_{\mathrm{e}} / \mathrm{q}_{\mathrm{e}}=1 / \mathrm{q}_{\mathrm{m}} \mathrm{K}_{\mathrm{L}}+\mathrm{C}_{\mathrm{e}} / \mathrm{q}_{\mathrm{m}}
$$

Where, $\mathrm{C}_{\mathrm{e}}$ is the equilibrium concentration $(\mathrm{mg} / \mathrm{L}), \mathrm{q}_{\mathrm{e}}$ is the amount of $\mathrm{Cr}(\mathrm{VI})$ adsorbed at equilibrium $(\mathrm{mg} / \mathrm{g})$ and $\mathrm{q}_{\mathrm{m}}$ is $\mathrm{q}_{\mathrm{e}}$ for a complete monolayer $(\mathrm{mg} / \mathrm{g}) ; \mathrm{K}_{\mathrm{L}}$ is sorption equilibrium constant $(\mathrm{L} / \mathrm{mg})$. A plot of $\mathrm{C}_{\mathrm{e}} / \mathrm{q}_{\mathrm{e}}$ versus $\mathrm{C}_{\mathrm{e}}$ (Figure 8 ) is to indicate a straight line graph of slope $1 / \mathrm{q}_{\mathrm{m}}$ and an intercept of $1 / \mathrm{K}_{\mathrm{L}} \mathrm{q}_{\mathrm{m}}$ [51]. Using the dimensionless separation factor, $\mathrm{R}_{\mathrm{L}}$, the Langmuir adsorption model can be used to predict the affinity between the adsorbent and adsorbate.

$$
\mathrm{R}_{\mathrm{L}}=1 /\left(1+\mathrm{K}_{\mathrm{L}} \mathrm{C}_{\mathrm{e}}\right)
$$

If the value of $R_{L}$ lies between $0-1$ the adsorption is said to be favorable, while $\mathrm{R}_{\mathrm{L}}>1$ represents unfavorable adsorption, and $\mathrm{R}_{\mathrm{L}}=1$ represents linear adsorption while the adsorption process is irreversible if $\mathrm{R}_{\mathrm{L}}=0$. From the analysis, the sorption equilibrium constant $\mathrm{K}_{\mathrm{L}}$ is 0.00903 $\mathrm{L} / \mathrm{mg}$. Chromium metal ion adsorption on the mixture of these animal bones follow the Langmuir adsorption model 
and the dimensionless quantity $\mathrm{R}_{\mathrm{L}}$ values for $\mathrm{Ce}(5.64,14.81, \quad 0.8559,0.8149,0.7730,0.6813$ and 0.5859 respectively. $18.65,25.15,32.52,51.81$ and 78.26$)$ are $0.9515,0.8820$,

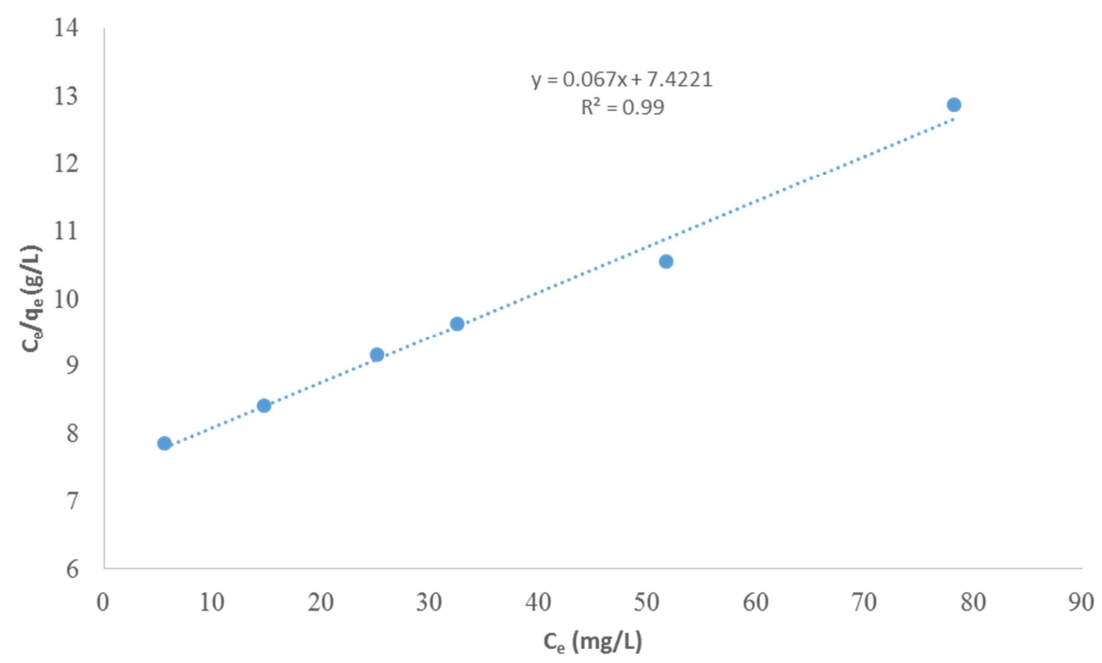

Figure 8. Langmuir Isotherm.

\section{Freundlich Isotherm}

Freundlich isotherm model has also been used to explain the results and validate the fitness of the results. The Freundlich isotherm is represented as follows.,

$$
\begin{gathered}
\log \mathrm{q}_{\mathrm{e}}=\log \mathrm{K}_{\mathrm{f}}+1 / \mathrm{n} \log \mathrm{C}_{\mathrm{e}} \\
\ln \mathrm{qe}=\mathrm{n} \ln \mathrm{Ce}+\ln \mathrm{Kf}
\end{gathered}
$$

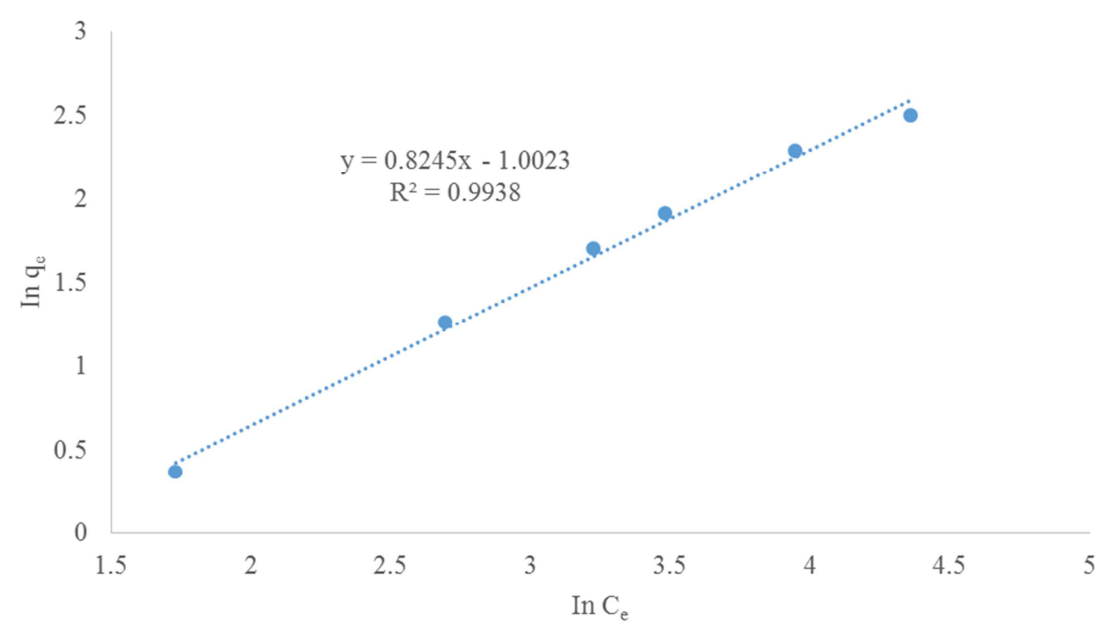

Figure 9. Freundlich Isotherm.

$\mathrm{C}_{\mathrm{e}}$ represents the equilibrium concentration $(\mathrm{mg} / \mathrm{L}), \mathrm{n}$ and $\mathrm{K}_{\mathrm{f}}$ represent constant incorporating all factors affecting the adsorption process such as intensity and adsorption capacity, respectively. A plot of In $\mathrm{q}_{\mathrm{e}}$ vs In $\mathrm{C}_{\mathrm{e}}$ (Figure 9) shows a linear graph with a slope of $n$ and intercept of $I_{n} K_{f}$. The $K_{f}$ value is related to the adsorption capacity; while the $\mathrm{n}$ value is related to the adsorption intensity (Equation 4 ). $n$ values explain the type of isotherm to be irreversible $(n=0)$, favourable $(0<n$ $<1)$ and unfavorable $(n>1)$ [52]. From the Freundlich isotherm (figure 9), the slope (n) and the intercept $\left(\mathrm{In} \mathrm{K}_{\mathrm{f}}\right)$ values are 0.8245 and -1.0023 respectively. The isotherm showed that the adsorption process is multilayer and apart from surface adsorption, parts of the adsorbate went into other layers on the surface of the adsorbent. The higher value of $\mathrm{R}^{2}=0.9938$ over the $\mathrm{R}^{2}$ value of Langmuir isotherm showed a better fitness of the adsorption process to Freundlich isotherm over Langmuir model.

\section{Conclusion/Recommendation}

The effectiveness of animal bone mixture as a low cost adsorbent in removal of chromium ion has been investigated. Best fit of linearity of concentration of chromium ion on the amount adsorbed by the adsorbent was pronounced evidently at $303 \mathrm{~K}$. 
The regression data analysis showed good fitness to Langmuir isotherm and better fitness to Freundlich isotherm. Mixed animal bone charcoal can be evaluated as an alternative adsorbent to treat waste water containing chromium before discharge into the aquatic environment. It can be applied in developing countries due to low cost and availability of cow bones.

\section{References}

[1] Ahmaruzzaman, M. (2011) Industrial Wastes as Low-Cost Potential Adsorbents for the Treatment of Wastewater Laden with Heavy Metals. Advances in Colloid and Interface Science, 166, 36-59.

[2] Kadirvelu, K., Thamaraiselvi, K. and Namasivayam, C. (2001) Removal of Heavy Metals from Industrial Wastewaters by Adsorption onto Activated Carbon Prepared from an Agricultural Solid Waste. Bioresource Technology, 76, 63-65.

[3] Ghrab, S., Benzina, M. and Lambert, S. (2017) Copper Adsorption from Wasterwater Using Bone Charcoal. Advances in Materials Physics and Chemistry, 7, 139-147. doi: 10.4236/ampc.2017.75012.

[4] Guptaa, S., Nayeka, S. and Sahab, R. N. (2010) Temporal Changes and Depth Wise Variations in Pit Pond Hydrochemistry Contaminated with Industrial Effluents with Special Emphasis on Metal Distribution in Water-Sediment System. Journal of Hazardous Materials, 183, 125-131.

[5] Kadirvelu, K., Thamaraiselvi, K. and Namasivayam, C. (2001) Removal of Heavy Metals from Industrial Wastewaters by Adsorption onto Activated Carbon Prepared from an Agricultural Solid Waste. Bioresource Technology, 76, 63-65.

[6] Kurniawan, T. A., Chan, G. Y. S., Lo, W. H. and Babel, S. (2006) Physico-Chemical Treatment Techniques for Wastewater Laden with Heavy Metals. Chemical Engineering Journal, 118, 83-98.

[7] Kolodynska, D., Geca, M., Siek, M. and Hubicki, Z. (2013) Nitrilotris (Methylene- phosphonic) Acid as a Complexing Agent in Sorption of Heavy Metal Ions on Ions Exchangers. Chemical Engineering Journal, 215-216, 948-958.

[8] Amin, N., Hussain, A., Alamzeb, S. and Begum, S. (2013) Accumulation of Heavy Metals in Edible Parts of Vegetables Irrigated with Waste Water and Their Daily Intake to Adults and Children, District Mardan, Pakistan. Food Chemistry, 136, 1515-1523.

[9] Tao, H. C., Lei, T., Shi, G., Sun, X.-N., Wei, X.-Y., Zhang, L.J. and Wu, W.-N. (2014) Removal of Heavy Metals from Fly Ash Leachate Using Combined Bioelectrochemical Systems and Electrolysis. Journal of Hazardous Materials, 264, 1-7.

[10] Chaari, I., Fakhfakh, E., Chakroun, S., Bouzid, J. and Boujelben, N. (2008) Lead Removal from Aqueous Solutions by a Tunisian Smectitic Clay. Journal of Hazardous Materials, $156,545-551$.

[11] Boujelben, N., Bouzid, J. and Elouear, Z. (2009) Adsorption of Nickel and Copper onto Natural Iron Oxide-Coated Sand from Aqueous Solutions: Study in Single and Binary Systems. Journal of Hazardous Materials, 163, 376-382.

[12] Moisés, T. P., Patricia, B. H., Barrera-Díaz, B. E., Gabriela, R. M. and Natividad-Rangel, R. (2010) Treatment of Industrial
Effluents by a Continuous System: ElectrocoagulationActivated Sludge. Bioresource Technology, 101, 7761-7766.

[13] Toque, J. A., Herliansyah, M. K., Hamdi, M., Ide-Ektessabi, A. and Wildan, A. M. (2007) The Effect of Sample Preparation and Calcination Temperature on the Production of Hydroxyapatite from Bovine Bone Powders. Proceedings of the 3rd Kuala Lumpur International Conference on Biomedical Engineering, Kuala Lumpur, Malaysia, 11-14 December 2007, 152-155.

[14] Wu, F. C., Tseng, R. L. and Juang, R. S. (2001) Kinetic Modeling of Liquid-Phase Adsorption of Reactive Dyes and Metal Ions on Chitosan. Water Research, 35, 613-618.

[15] Barakat, N. A. M., Khalil, K. A., Faheem, A., Sheikh, A. M. and Omran, M. (2008) Physiochemical Characterizations of Hydroxyapatite Extracted from Bovine Bones by Three Different Methods: Extraction of Biologically Desirable. Materials Science and Engineering C, 28, 1381-1387.

[16] Cechinel, M. A. P., Ulson de Souza, S. M. A. G. and Ulson de Souza, A. A. (2014) Study of Lead (II) Adsorption onto Activated Carbon Originating from Cow Bone. Journal of Cleaner Products, 65, 342-349.

[17] Pérez, J. T., Solache-Rios, M. and Colin-Cruz, A. (2008) Sorption and Desorption of Dye Remazol Yellow onto a Mexican Surfactant-Modified Clinoptilolite-Rich Tuff and a Carbonaceous Material from Pyrolysis of Sewage Sludge. Water, Air, and Soil Pollution, 187, 303-313. https://doi.org/10.1007/s11270-007-9518-6

[18] Bansal RC, Goyal M, Activated Carbon Adsorption, CRC Press, USA, 2005, 1-5.

[19] Reynolds TD, Richards PA, Unit operation and processes in environmental Engineering, 2nd Edition PWS Publishing. 1996.

[20] Fishel FM, Activated charcoal for pesticide deactivation (University ofFlorida extension, 2008) PI 164.

[21] Nworu J. S., Oparanozie T. I., Ogbolu B. O., Onunkwo I. C and Osideru O. O. (2018). "Spectrophotometric Evaluation of Heavy Metal Speciation in Lead-Zinc Mine Soil from Enyigba in Ebonyi State." IOSR Journal of Applied Chemistry (IOSR$J A C)$. 11: 10 18-24.

[22] Huidong Li, Zhao Li, Ting Liu, Xiao Xiao, Zhihui Peng and Le Deng, (2008). "A novel technology for biosorption and recovery hexavalent chromium in wastewater by biofunctional magnetic beads", Bioresource Technology. 99 (2008) 6271-6279.

[23] Jorge L. Brasil, Ricardo R. Eva, Caroline D. Milcharek, Lucas C. Martins, Flavio A. Pavan, Araci A. dos Santos Jr., Silvio L. P. Dias, Jairton Dupont, Caciano P. Zapata Noren and Eder C. Lima, "Statistical design of experiments as a tool for optimizing the batch conditions to $\mathrm{Cr}$ (VI) biosorption on Araucaria angustifolia wastes", Journal of Hazardous Materials B. 133 (2006) 143-153.

[24] Jinshao Ye, Hua Yin, Bixian Mai, Hui Peng, Huaming Qin, Baoyan $\mathrm{He}$ and $\mathrm{Na}$ Zhang, "Biosorption of chromium from aqueous solution and electroplating wastewater using mixture of Candida lipolytica and dewatered sewage sludge", Bioresource Technology. 101 (2010) 3893-3902.

[25] Jang, A., Sco, Y. and Bishop, P. L., "The removal of heavy metals in urban runoff by sorption on mulch", Environmental Pollution. 133 (2005) (1) 117-127. 
[26] Lei Yang and Paul Chen, J., "Biosorption of hexavalent chromium onto raw and chemically modified Sargassum sp.", Bioresource Technology. 99 (2008) 297-307.

[27] Levankumar Lakshmanraj, Ayyanar Gurusamy, Gobinath, M. B. and Chandramohan, R., "Short communication Studies on the biosorption of hexavalent chromium from aqueous solutions by using boiled mucilaginous seeds of Ocimum americanum", Journal of Hazardous Materials. 169 (2009) $1141-1145$.

[28] Liping Deng, Yang Zhang, Jie Qin, Xinting Wang and Xiaobin Zhu, "Biosorption of $\mathrm{Cr}$ (VI) from aqueous solutions by nonliving green algae Cladophora albida", Minerals Engineering. 22 (2009) 372-377.

[29] Margarita Enid R. Carmona, Monica Antunes Pereira da Silva and Selma G. Ferreira Leite, "Biosorption of chromium using factorial experimental design", Process Biochemistry. 40 (2005) 779-788.

[30] Murphy, V., Hughes, H. and McLoughlin, P., "Comparative study of chromium biosorption by red, green and brown seaweed biomass", Chemosphere. 70 (2008) 1128-1134.

[31] Neetu Tewaria, Vasudevana, P. and Guhab, B. K., "Study on biosorption of $\mathrm{Cr}$ (VI) by Mucor hiemalis", Biochemical Engineering Journal. 23 (2005) 185-192.

[32] Ozgur Dogan Uluozlu., Ahmet Sari, Mustafa Tuzen and Mustafa Soylak, "Biosorption of $\mathrm{Pb}$ (II) and $\mathrm{Cr}$ (III) from aqueous solution by lichen (Parmelina tiliaceae) biomass", Bioresource Technology. 99 (2008) 2972-2980.

[33] Supriya Singh, Tripathi Alka, Srivastava S. K., Ram Prakash (2013). Removal of Hexavalent Chromium by Using Mangifera Indica Bark (Biosorption). Ram Prakash et al. Int. J. Res. Chem. Environ. Vol. 3 Issue 4 October 2013 (61-67).

[34] Sharma D. C. and Forster C. F., A Preliminary examination into the adsorption of hexavalent chromium using Low-cost adsorbents, Bioresource Technology, 47, 257-264 (1994).

[35] Gupta S \& Babu B. V. Adsorption of Chromium (VI) by low cost adsorbent prepared from tamarind seed. Journal of Environmental Engineering and Science, 7 (5), 553-557 (2008).

[36] Orhan Y. and Buyukgungur, H. The removal of heavy metals by using agricultural wastes, Water Science Technology, 28 (2), 247-255 (1993).

[37] Namasivayam C., Yamuna R. T., Adsorption of chromium (VI) by a low-cost adsorbent: biogas residual slurry. Chemosphere 30 (3), 561-578 (1995).

[38] Ahmad Said, M. Supwatul Hakim, and Yuli Rohyami (2014). The Effect of Contact Time and $\mathrm{pH}$ on Methylene Blue Removal by Volcanic Ash. Int'l Conference on Chemical, Biological, and Environmental Sciences (ICCBES'14) May 12-13, 2014 Kuala Lumpur (Malaysia).

[39] Nworu Jerome Sunday, Ngele Sylvester Okechukwu, Nwabueze Elom, Okhifo Anthony, Peretomode Tekena Michael. Quantitative Characterization of Activated Carbon from Cow, Donkey, Chicken and Horse Bones from Ezzangbo in Ebonyi State, Nigeria. American Journal of Applied Chemistry. Vol. 6, No. 5, 2018, pp. 169-174. doi: 10.11648/j.ajac.20180605.12.

[40] Y. C. Sharma, C. H. Weng, Removal of chromium (VI) from water and wastewater by using riverbed sand: Kinetic and equilibrium studies, J. Hazard. Mater. 142 (2007) 449-454.

[41] S. M. Lee, W. G. Kim, C. Laldawngliana, D. Tiwari, Removal Behavior of Surface Modified Sand for Cd(II) and Cr(VI) from Aqueous Solutions, J. Chem. Eng. Data 55 (2010) 30893094.

[42] H. Katsumata, S. Kaneco, K. Inomata, K. Itoh, K. Funasaka, Masuyama, T. Suzuki, K. Ohta, Removal of heavy metals in rinsing wastewater from plating factory by adsorption with economical viable materials, J. Environ. Manage. 69 (2003) 187-191.

[43] P. Chowdhury, P. Mondal, K. Roy, Synthesis of cross-linked graft copolymerfrom [2-(methacryloyloxy)ethyl] trimethylammonium chloride and poly(vinyl alcohol) for removing chromium(VI) from aqueous solution, Polym. Bull. 64 (2010) 351-362.

[44] M. R. Samani, S. M. Borghei, A. Olad, M. J. Chaichi, Removal of chromium from aqueous solution using polyaniline - Poly ethylene glycol composite J. Hazard. Mater. 184 (2010) 248-254.

[45] V. Neagu, S. Mikhalovsky, Removal of hexavalent chromium by new quaternized crosslinked poly(4-vinylpyridines) $\mathrm{J}$. Hazard. Mater. 183 (2010) 533-540.

[46] S. Deng, R. Bai, Removal of trivalent and hexavalent chromium with aminated polyacrylonitrile fibers: performance and mechanisms, Wat. Res. 38 (2004) 2424-2432.

[47] Y. Nakano, K. Takeshita, T. Tsutsumi, Adsorption mechanism of hexavalent chromium by redox within condensed-tannin gel, Wat. Res. 35 (2001) 496-500.

[48] P. A. Kumar, S. Chakraborty, M. Ray, Removal and recovery of chromium from wastewater using short chain polyaniline synthesized on jute fiber, Chem. Eng. J. 141 (2008) 130-140.

[49] X. Hua, J. Wang, Y. Liua, X. Li, G. Zeng, Z. Bao, X. Zeng, A. Chen, F. Long, Adsorption of chromium (VI) by ethylenediamine-modified cross-linked magnetic chitosan resin: Isotherms, kinetics and thermodynamics, J. Hazard. Mater. 185 (2011) 306-314.

[50] Animesh Agarwal and Puneet Kumar Gupta (2015). Adsorption Study of $\mathrm{Cr}(\mathrm{VI})$ from Aqueous Solution Using Animal Bone Charcoal as Low Cost Adsorbent. International Journal of Engineering Technology, Management and Applied Sciences. Volume 3 Issue 1, ISSN 2349-4476.

[51] I. Langmuir, The constitution and fundamental properties of solids and liquids, J. Am. Chem. Soc. 38 (1916) 2221-2295.

[52] N. M Mahmoodi, M Arami, Modelling and sensitivity analysis of dyes adsorption onto natural adsorbent from colored textile wastewater, J. Appl. Polym. Sci, 109: (2008), 4043-4048. 